\title{
ТВОРЧЕСКИЙ ПОТЕНЦИАЛ ПОДРОСТКОВ И ТЕАТРАЛЬНАЯ ПЕДАГОГИКА
}

\section{CREATIVE POTENTIAL OF TEENAGERS AND THEATER PEDAGOGY}

M. Gurenko

Summary: In the article, the author examines the concept of theatrical pedagogy, its role, methods and techniques. The goal, objectives and methods used by the author to research issues on this topic are determined. The features of adolescence are analyzed. The concept and features of cognitive interest, features of cognitive interest in adolescent children are considered. The author determined that thanks to theatrical art, a teenager acquires a number of invaluable priorities. The problems of the formation of the creative potential of adolescent children are revealed. The conditions for the development of creative principles in a teenage child are determined. The author believes that theatrical art affects the development of the multifaceted personality of the new era. The article describes the means, forms and methods of theatrical pedagogy. The author traces the relationship between the use of theatrical pedagogy and the development of imagination, the emotional sphere, the fantasy of adolescents, and his creative principles. Having solved the tasks set at the beginning of the study, the author achieved the goal of the study: the author determined that theatrical activity contributes to the identification and selection of individuality, the uniqueness of the human personality, the creative person, since the main thing in theatrical activity is the bright color of the emotional background, which contributes to the development of creative potential in adolescent children.

Keywords: theatrical pedagogy, creativity, methodology, organization, student, motivation, interest, classes, theatrical activity, personality.
Д вижущая сила прогресса в современном мире, который характеризуется многовариативностью нашего общества, постоянными процессами взаоникновения общественных групп, наций, экономических моделей развития, - личность, индивидуальность человека, что на сегодня стало доминантой в самых массовых процессах и движениях. Это обуславливает потребность в поиске новых путей содействия максимальному раскрытию творческих качеств личности подростка.

Подростковому возрасту требуется максимум внимания, так как подростковый период - это период становления личности [1]. В этом возрасте интенсивно развиваются внутренние творческие силы, возможности; формируется самооценка подростков, влияющая на успехи в обучении и т.д. Когда реализуется психический познавательный процесс, происходит также изменение

\author{
Гуренко Максим Владимирович \\ аспирант, Тамбовский государственный университет \\ имени Г.Р. Державина \\ maxsimum14@mail.ru
}

Аннотация: В статье автор рассматривает понятие театральной педагогики, ее роль, методы и приемы. Определяется цель, задачи и методы, которыми пользовался автор для исследования вопросов по данной теме. Проанализированы особенности подросткового возраста. Рассмотрено понятие и особенности познавательного интереса, особенности познавательного интереса у детей подросткового возраста. Автором определено, что благодаря театральному искусству подросток приобретает ряд неоценимых приоритетов. Выявлены проблемы формирования творческого потенциала детей подросткового возраста. Определены условия развития творческих начал в ребенке подросткового возраста. Автор считает, что театральное искусство влияет на развитие многогранной личности нового времени. В статье описываются средства, формы и методы театральной педагогики. Автор прослеживает взаимосвязь использования театральной педагогики и развития воображения, эмоциональной сферы, фантазии подростков, его творческих начал. Решив задачи, поставленные в начале исследования, автор достиг цели исследования: автором определено, что театрализованная деятельность способствует выявлению и выделению индивидуальности, единственности человеческой личности, творческого человека, так как главное в театрализованной деятельности - яркая окрашенность эмоционального фона, что и способствует развитию творческого потенциала у детей в подростковом возрасте.

Ключевые слова: театральная педагогика, творческие способности, методика, организация, обучающийся, мотивация, интерес, занятия, театральная деятельность, личность.

интересов подростка, вызванный процессом формирования личности. При этом подросток изменяет направление сферы собственных интересов, они становятся более выборочными, отмечаются определенной устойчивостью. Однако, учеба и все, что с ней связано, становится менее интересным подростку.

Цель данной работы - определить возможность формирования творческого потенциала подростка средствами театральной педагогики. Для достижения данной цели необходимо решение следующих задач: рассмотреть понятие театральной педагогики, ее роль, методов и приемов; проанализировать особенности подросткового возраста; выявлены проблемы формирования творческого потенциала детей подросткового возраста; проследить взаимосвязь использования театральной педагогики и развития воображения, эмоциональной сферы, фантазии подростков, его творческих начал. 
В работе был использован ряд эмпирических методов, таких как изучение различных источников информации, анализ полученных сведений.

Познавательные интересы имеют количественную и качественную характеристику. Количественная характеристика является характерной во время процесса решения задач интеллектуального плана, определения скорости, эффективности. Качественную сторону характеризуется процессом изменений в структуре мыслительного процесса подростка, которому уже становится небезразлично, каким образом будет решаться та или иная задача. Все это является подтверждением того, что подростковый возраст - период трансформации именно интеллектуальной сферы [2].

Развитие творческих начал в подростковом возрасте исследовали многие специалисты (Л.С. Выготский, А.В. Мудрик, Д.И. Фельдштейн), считающие подростковый возраст сензитивным периодом для развития творческого потенциала, оказывающим влияние на становление личности в целом [3].

Каждый человек стремится к творчеству, что можно определить в качестве естественного двигателя культуры. Творчество - реализация неких потребностей людей, посредством которым происходит осмысление действительности. Стремление к творчеству - это путь духовного развития личности любого человека, раскрытие его творческого потенциала.

Под творческим потенциалом стоит понимать все качества человека, которыми определяется его возможности и рамки его участия в любого рода деятельности.

Процесс развития творческого потенциала - это определенный процесс, характеризующийся непрерывностью, целенаправленностью. Этот процесс делает более актуальными ряд личных механизмов, способствующих проявлению возможностей, процессов саморазвития, самореализации, главным условием реализации которого является наличие доминирования роли формирования творческой направленности личности, что возможно, в том числе, обращением к культуре, что стимулирует стремление перехода от идеи «образованного человека» к идее «человека культуры». Благодаря такому переходу появляется возможность выявить взаимосвязь таких сфер, как образование, культура, искусство и личность.

Стоит отметить, что благодаря театральному искусству подросток приобретает ряд неоценимых приоритетов, представленных далее [4]:

- уверенность в собственных силах, способность к рассуждению, утверждению в качестве личности,
- приобретение навыков коллективного общения, которое необходимо подросткам в будущей жизни,

- процесс воспитания собственного чувства ответственности и самостоятельности,

- возможность к творческому самовыражению, к реализации персональных способностей каждого подростка,

- соприкосновение через игру с явлениями реальной действительности, переживаниями, что наполнит внутренний мир подростка богатым содержанием, надолго оставив в его памяти след,

- развиваются задатки и творческие качества,

- дети становятся более дисциплинированными, обладают большей самодисциплиной,

- формируется вкус, воспитывается чувство меры, ребенок обретает способность анализа, отличает истинное и высокое от пошлого и фальшивого, подросток может объективно оценивать собственные возможности и т.д.,

- расширяется кругозор, что способствует получению дополнительных знаний, необходимых для дальнейшей жизни.

Таким образом, театральное искусство влияет на развитие многогранной личности нового времени. Можно даже утверждать, что благодаря театральному искусству личность может обрести весь арсенал «оружий», так необходимых современному человеку: человек становится более самоуверенным, больше полагается на себя и собственные силы; усиливается чувство ответственности за собственные поступки; развивается умение отстаивать собственное мнение, точку зрения и т.д. [5]

Личность современного человека становится более гармоничной, что полностью совпадает с потребностями общества нового времени. Именно таким путем познания и идет театральная педагогика.

Собственно, понятие «театральная педагогика» на сегодня имеет неоднозначную трактовку у разных специалистов.

Под театральной педагогикой в общем понимается такое направление современной психологии и педагогики искусства, осуществление которого позволяет реализовать такие принципы, как событийность, проживание, личностное творческое действие, возможность импровизировать. Все перечисленные принципы взаимосвязаны благодаря интеллектуальному, чувственному и эмоциональному восприятию [6].

Посредством театральной педагогики возможно создание открытой творческой среды для живого общения, где темы для диалога могут быть крайне разнообразны. 
Однако цель такого общения - работа по формированию целостной картины мира, удовлетворение в потребности развития одновременно эмоциональных и интеллектуальных способностей.

В процессе реализации театральной педагогики задействованы определенные методы. Благодаря их реализации более эффективно формируется, например, творческое воображение, составление необходимого анализа, синтеза полученной информации. Благодаря реализации методов театральной педагогики человек может самостоятельно организовывать собственные психические проявления, корректировать свое поведение и т.д. [7].

Выделен базовый метод театральной педагогики. Это метод физического воздействия. Он основан на анализе полученной информации, предложенного произведения. Продолжением анализа является процесс выстраивания логических цепочек, образующих сквозное действие.

В качестве следующего метода стоит отметить метод исторических параллелей. Отличительная черта данного метода - проведение аналогий, сравнений в эмоционально-логических представлениях, свойственных различным исторических эпохам и периодам развития общества. Это способствует более продуктивному решению поставленных задач посредством обеспечения понимания коммуникативной стороны учебного процесса.

Метод действенного анализа в театральной педагогике можно отнести к способам выработки навыков волевого поведения. Иначе такое поведение называют «сценическим» [8]. При реализации данного метода происходит акцентирование внимания на умении использовать те или иные элементы техники речи.

Также стоит отметить использование в театральной педагогике этюдного метода, под которым понимается проведение творческого исследования какого-либо жизненного действия, поступка того или иного человека, события.

Не менее важным в театральной педагогике и также не менее популярным считается метод игрового театрализованного представления.

Стоит напомнить, что основоположники отечественной театральной педагогики - видные деятели театра Щепкин, Давыдов, Варламов, режиссер Ленский. Но качественно новым этапом в театральной педагогике стоит считать период деятельности основателей МХАТа Станиславского и Немировича-Данченко [9].

Применение театральной педагогики при работе с подростками способствует созданию определенных ситуаций, при которых моделируются жизненные ситуации. Подростки «переживают» эти ситуации вместе с педагогом, который вводит детей сквозь эту модель в мир всечеловеческой культуры.

Театральное искусство для подростка - модель, хотя и сложной по воспроизведению, но интересной деятельностью. Театральное искусство для подростка это некая модель жизни. Продуктивнее и качественнее формируется творческий потенциал подростка именно посредством реализации процесса театральной педагогики во время формирования коллектива единомышленников. В качестве таких коллективов можем рассматривать театральные студии, кружки и т.д.

Когда театр постигается подростком с приложением собственных сил, опыта, подросток получает более четкое представление об окружающем. Подросток начинает более полно ощущать себя в этом окружающем мире.

Театральную педагогику характеризует двойственность социальной направленности. Одна сторона - процессы, благодаря которым происходит воздействие на личность подростка, который является объектом приложения методов и форм театральной педагогики, т.е. подросток является актером на сцене. Другая сторона - это воздействие на зрителя с участием подростков, участвующих в кружках, студиях и т.д. [10]

Что же касается средств театральной педагогики, то стоит отметить мощность воздействия на эмоциональную сферу подростка, безусловность влияния на то, как действует ребенок, какие поступки он совершает, какой выбор осуществляет.

Современное общество характеризуется множеством нерешенных социальных проблем, что обязательно учитывается при выборе средств и форм театральной педагогики. Так, театрализованная деятельность в подростковом коллективе способна раскрывать творческий потенциал ребенка, воспитывать творческую направленность личности.

Подросток легче замечает в окружающем мире интересные идеи, более продуктивно их воплощает, создает художественный образ, тем самым развивая творческое воображение, ассоциативное мышление. Подростки умеют видеть необычные моменты в самых обыденных предметах, событиях [11]. Поэтому театрализованную деятельность в подростковом коллективе нужно направлять на целостное воздействие на личность ребенка, раскрепощать его, стимулировать на самостоятельность в творчестве, способствовать развитию ведущих психических процессов, самопознанию и само- 
выражению личности; создавать условия для большей социализации, в чем зачастую нуждаются именно дети подросткового возраста, усиливать их адаптационные способности и т.д.

При выборе форм театрализованной педагогики должны приниматься во внимание личность подростка, его индивидуальность, своеобразие, право проявления собственного «я» и т.д. При этом методика работы с детьми должна быть не только коллективной, но и ориентироваться на индивидуальное развитие творческой личности каждого подростка.

Для ребенка любого возраста, и тем особенно для ребенка подросткового возраста, творческий потенциал является наиболее важным. И взрослые ни в коем случае не должны игнорировать это. Как уже было сказано, особенно актуальным это является для подростков, так как дети уже обладают определенными знаниями, обладают желаниями в развитии и в познании в определенных областях, наделены определенной долей любопытства, пытаются выразить себя. Подростковый возраст требует поощрения творческого потенциала любыми возможными способами.

Именно театрализованная деятельность способствует выявлению и выделению индивидуальности, единственности человеческой личности, творческого человека. Слово «творчество» берет свое начало от слова «творить», а значит, создавать что-то новое, интересное [12]. При этом работа с подростком осложняется еще и тем, что нужно учитывать то, что «новое» и его создание зачастую может не получаться. И именно театрализованная деятельность направлена на развитие в ребенке самостоятельности, независимости, оригинальности мышления.

Творчество также стоит воспринимать как непрерывность роста. Невозможно лишь подумать о чем-то, и сразу, без подготовки, это реализовать. Но в этом-то и заключается человеческое развитие, прогресс, общение.

В полной мере потребность в общении может удовлетворить театрализованная деятельность. Сфера общения дает возможность обогатить содержание самого общения, углубить познание другого человека, развить коммуникативные навыки, выразить себя, проявить себя с творческой стороны.

Главное в театрализованной деятельности - яркая окрашенность эмоционального фона. Театрализованная деятельность позволяет добавить и раскрыть собственные душевные переживания. Концентрируется творческий потенциал всех участников театрализованной деятельности, что позволяет всем участникам этой деятельность самореализоваться, самоактуализироваться [1].

Для развития творческого начала в ребенке такого сложного подросткового возраста, для увеличения степени творческого потенциала целесообразно создание совместно с детьми театрализованных представлений с применением произведений русского народного творчества, по произведениям не только отечественной, но и зарубежной классики и т.д. Но наиболее главным при реализации театральной педагогики в воспитании творческого потенциала подростка можно считать развитие его эмоциональной сферы, его чувств, души, веры в себя, в свою неповторимость и уникальность.

Подводя итог вышесказанному, стоит отметить, что то, как, каким путем, посредством каких методов и приемов пытаться раскрыть творческий потенциал подростка способствует и эффективно решает именно театральная педагогика.

Театральная педагогика в качестве симбиоза произведения культуры и социума должна быть обеспечена собственным местом в образовательном процессе. В качестве оптимального условия социокультуры принимается в том числе театральная деятельность. И именно это стимулирует развитие творческих способностей [13]. Театральную педагогику отличает интегративность характера. Значит, театральная педагогика делает актуальными приобретенные знания, способности, которые формируются в процессе театрализованной деятельности. Театральная педагогика является мотиватором к проявлению творческих способностей.

Использование средств театральной педагогики не будет успешным без изучения психологии подростка, без сопереживания ему, что даст возможность расширению эмоциональной отзывчивости, развития гибкости души. Так как именно эти качества сегодня наиболее востребованы в обществе и именно такие качества необходимы подрастающему поколению, характер и привычки у которого только формируются. Привитие и воспитание данных качеств обязательно вызовет со стороны ребенка полную творческую отдачу.

В заключение следует отметить, что театральная педагогика - особенное средство, достаточного для охвата каждого этапа формирования становления творческих способностей подростка в духовном освоении окружающего мира и в осознании собственных потенциальных возможностей специфическими театральными средствами. 


\section{ЛИТЕРАТУРА}

1. Караковский В.А., Новикова Л.И., Селиванова Н.Л. Воспитание? Воспитание... Воспитание! - Москва, 2015.

2. Архангельский, Л.М. Ценностные ориентации и нравственное развитие личности / Л.М. Архангельский. - М.: Знание, 2018. - 64 с.

3. Фридман, Л.М. Изучение личности учащегося и ученических коллективов: книга для учителя. - М.: Просвещение, 2018. - 206с.

4. Азаров 0.Г. Современные научные психолого-педагогические подходы к пониманию творческой личности/0.Г. Азаров//Вестник Ставропольского гос. ун-та, - Вып.64, 2019. - Ставрополь: Изд-во СГУ, 2009. - С. 23- 34.

5. Шульга, И.И. Педагогическая анимация: Профессиональная подготовка организатора детского досуга / И.И. Шульга. - Новосибирск: НГПУ, 2016. - 340 с.

6. Букатов, В.М. Театральные технологии в гуманизации процесса обучения школьников: дисс. ... д-ра пед.наук / В.М. Букатов. - М., 2016. - 376 с.

7. Сериков, В.В. Развитие личности в образовательном процессе: монография / В.В. Сериков. - М.: Логос, 2015. - 448 с.

8. Бухвалов В.А. Развитие учащихся в процессе творчества и сотрудничества/ Бухвалов В.А. — М.: Просвещение 2016. - 167 с.

9. Сетрукова, Л. Театральная педагогики в школе [Текст] / Л. Сетрукова // Педагогика. - 2016. - №4. - C.121-123.

10. Давыдов, В.Г. От детских игр к творческим играм и драматизациям / В.Г. Давыдов // Театр и образование: сб. науч. тр. - М., 2017.

11. Савостьянов, А.И. Общая театральная психология [Текст] / А.И. Савостьянов. - СПб.: КАРО, 2017. - 256 с.

12. Ершова, А.П. Эстетическая значимость театрального творчества школьников / А.П. Ершова // Искусство в школе. - 2020. - № 5. - С. 40-43.

13. Яковлюк С.М., Ионов-Тарасов И.В. Методы и приемы театральной педагогики в формировании коммуникативной культуры школьника // Интернет-журнал «Мир науки» 2016, Том 4, номер 2

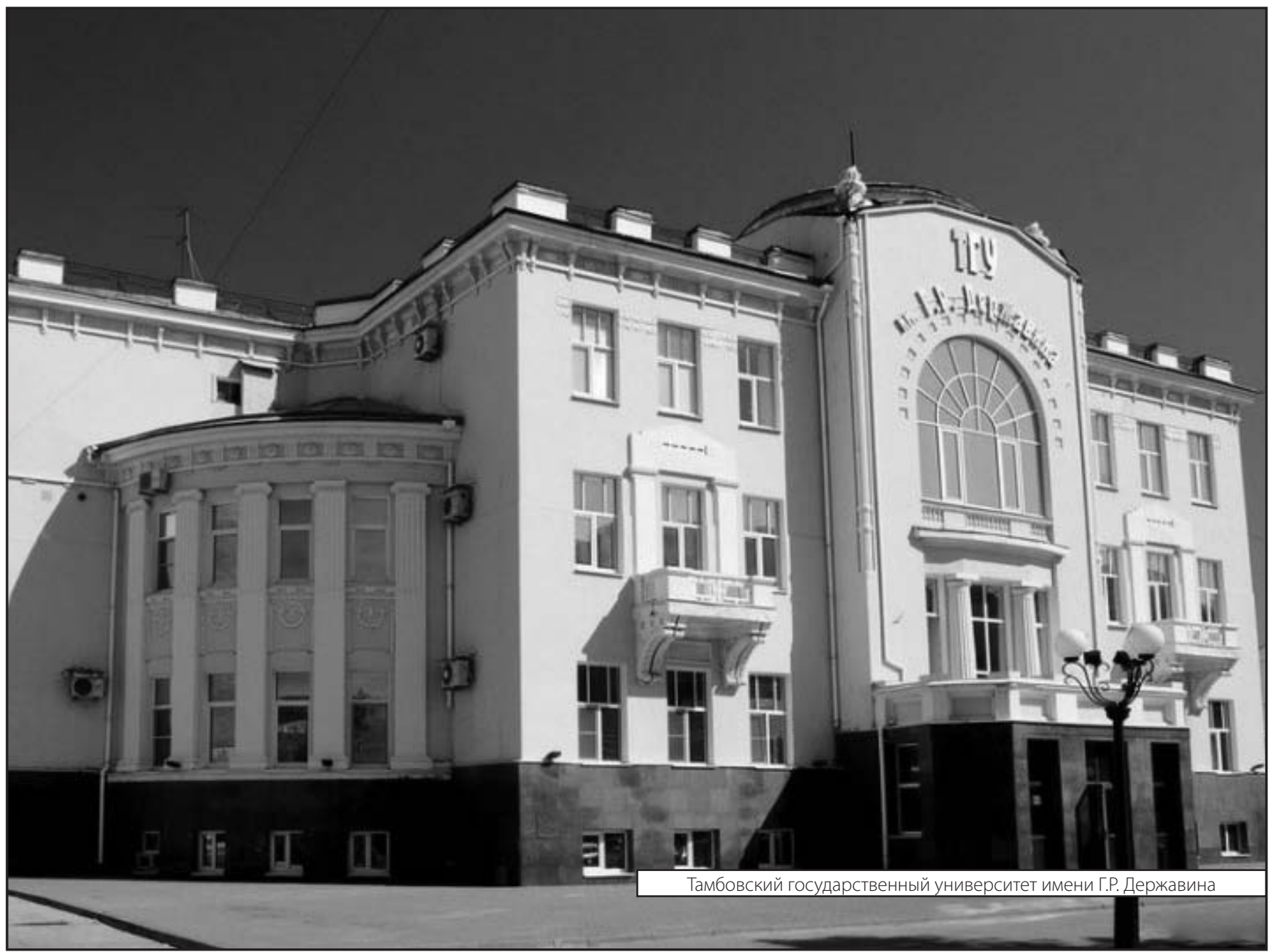

